Article

\title{
Fabrication of Size-Tunable Metallic Nanoparticles Using Plasmid DNA as a Biomolecular Reactor
}

\author{
Jacopo Samson ${ }^{1}$, Irene Piscopo ${ }^{2}$, Alex Yampolski ${ }^{1}$, Patrick Nahirney ${ }^{3}$, Andrea Parpas ${ }^{1}$, \\ Amit Aggarwal ${ }^{1}$, Raihan Saleh ${ }^{1}$ and Charles Michael Drain ${ }^{1,4, *}$
}

1 Department of Chemistry, Hunter College of the City University of New York, 695 Park Avenue, New York, NY 10065, USA; E-Mails: jsamson@hunter.cuny.edu (J.S.);

yampolsa@gmail.com (A.Y.); aparpas@hunter.cuny.edu (A.P.); amitashin@yahoo.co.in (A.A.); raihan.saleh@gmail.com (R.S.)

2 EM Consulting, 57 Soundview Drive, Huntington, NY 11743, USA;

E-Mail: irene.piscopo@gmail.com

3 Division of Medical Sciences, University of Victoria, Victoria, BC V8W 2Y2, Canada;

E-Mail: nahirney@uvic.ca

4 The Rockefeller University, 695 Park Avenue, New York, NY 10065, USA

* Author to whom correspondence should be addressed; E-Mail: cdrain@hunter.cuny.edu; Tel.: +1-212-650-3791; Fax: +1-212-722-5332.

Received: 28 July 2011; in revised form: 26 September 2011 / Accepted: 10 October 2011 /

Published: 21 October 2011

\begin{abstract}
Plasmid DNA can be used as a template to yield gold, palladium, silver, and chromium nanoparticles of different sizes based on variations in incubation time at $70{ }^{\circ} \mathrm{C}$ with gold phosphine complexes, with the acetates of silver or palladium, or chromium acetylacetonate. The employment of mild synthetic conditions, minimal procedural steps, and aqueous solvents makes this method environmentally greener and ensures general feasibility. The use of plasmids exploits the capabilities of the biotechnology industry as a source of nanoreactor materials.
\end{abstract}

Keywords: plasmid DNA; biomolecular reactor; gold; silver; palladium; chromium nanoparticles; green synthesis 


\section{Introduction}

Gold nanoparticles (Au NPs) and other metallic based nanoparticles (e.g., nickel, silver, palladium, chromium) are synthesized by a variety of methods because of their wide range of potential applications, e.g., drug delivery systems, catalysts, optical sensors, and antimicrobial agents [1-8]. However, the harsh conditions employed in several synthetic approaches has motivated researchers to investigate milder routes to obtain metal NP [9]. Organic molecules and inorganic molds can be used to control NP growth and dimensions [8]. Though confusing, the literature refers to "templates" both as sites where NP are formed and as a means to organize the NP into hierarchal patterns. The formation of inorganic NP in nature, such as the complex morphologies of carbonate [10], ferritin [11-13], and other NP [14] has inspired significant efforts to form and organize NP using biological systems[15]. Macromolecules can serve as a scaffold where NP form and bind, or as a nanoreactor (mold) that determines the size of the forming NP. In both cases nucleation can be on the macromolecule. Biological systems such as proteins [16], viruses [17], and plasmid DNA [18] were shown to be successful scaffolds or molds enabling milder pathways for the formation of NP. To date, the methodologies employing biological reagents present other drawbacks such as poor size tunability, broad dispersity, and limited shape control. The tendency of cationic gold to disproportionate in aqueous solutions [19], and issues centered on stabilizing metallic NPs further complicate synthetic methods based on biological macromolecules.

We previously demonstrated that the toroidal topology of plasmid DNA is a viable mold for the formation of gold $(\mathrm{Au})$, nickel $(\mathrm{Ni})$ and cobalt $(\mathrm{Co})$ NP. Plasmid DNA is readily available, inexpensive, and the size of the NP is tunable based on length of the biopolymer and the inner diameter of the toroid [18]. The size of the NP formed also is dictated by several varying parameters that influence the particle formation mechanism, e.g., G-C versus A-T content and different degrees of topological purity of the plasmid suspensions. The previous report used UV light to catalyze photo-oxidative degradation of the plasmid DNA with the concomitant reduction of the metal ions. Thus, the reproducibility is also dependent on maintaining a specific energy flux during the irradiation time [18].

Herein, we present a complementary synthetic method based on a kinetic approach wherein the plasmid DNA (pcDNA 3.1(+)/GFP, approx. $6 \mathrm{kbps}$ ) acts as a nanoreactor to initiate and control the formation of $\mathrm{Au}$ and other metallic NPs by incubation at elevated temperatures. This is an easy to follow procedure that requires less energy, time, and reagents than many other templating systems [14]. The size of the Au NPs can be controlled by varying the incubation times (Figure 1). Similar procedures allow the preparation of other NP including silver (Ag), palladium (Pd), and chromium $(\mathrm{Cr})$. In this method the metal ions are reduced by oxidative degradation of the amine buffer and/or the DNA at elevated temperatures, and disproportionation reactions for Au, thereby obviating the need for auxiliary reducing agents such as hydrazine and sodium borohydride. 
Figure 1. Incubation time of the gold phosphine precursor with plasmid DNA versus NP size determined by TEM analysis.

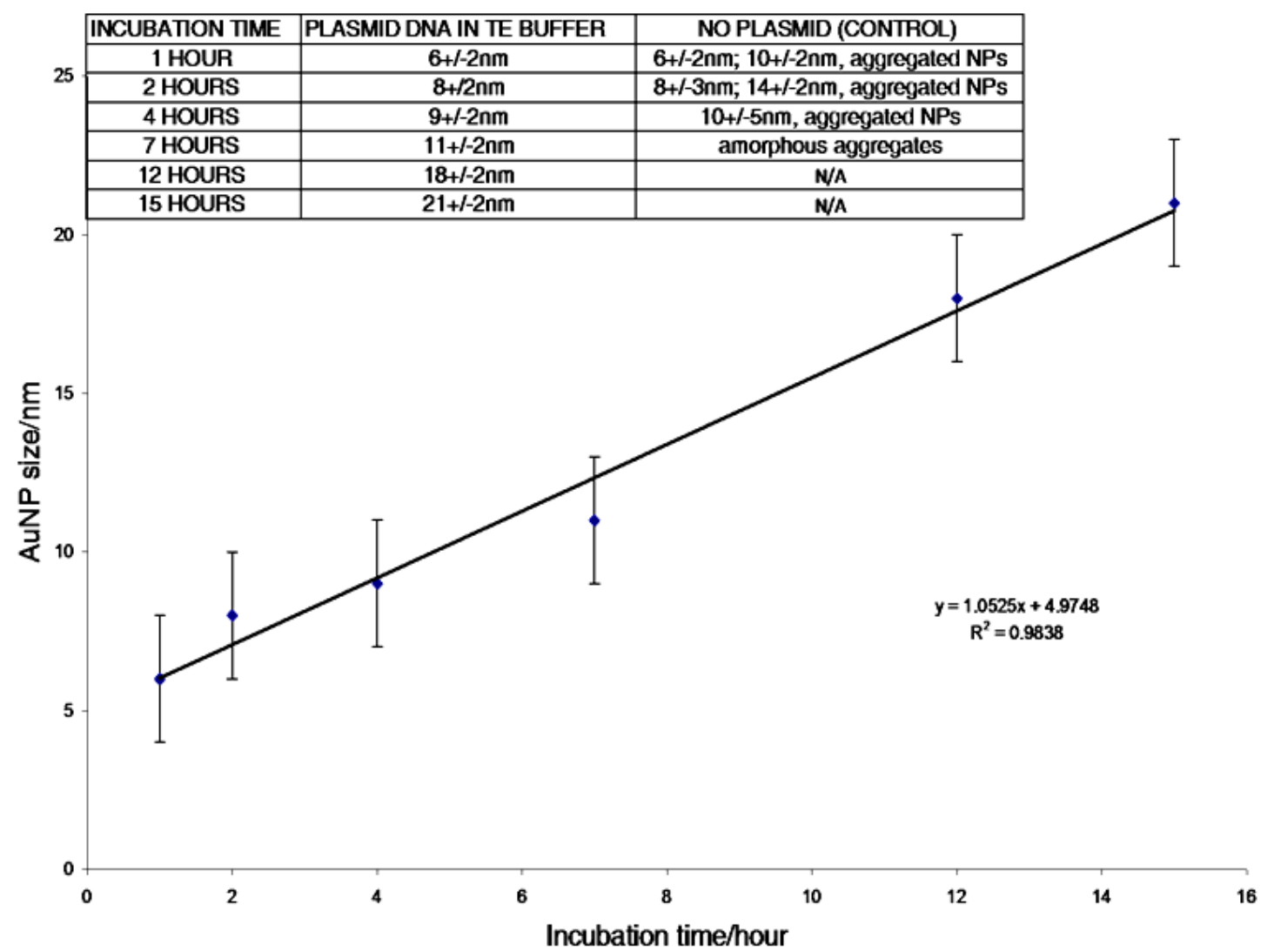

\section{Experimental Section}

\subsection{Instrumentation and Materials}

\subsubsection{UV-Visible}

A Beckman Coulter DU800 spectrophotometer was used where $50 \mu \mathrm{L}$ of each sample was loaded into the $8 \mathrm{~mm}$ path length cell. PCR Eppendorf tubes were used. Silver acetate, cadmium acetonalacetonate, palladium acetate, and tris(hydroxymethyl)-aminomethane (Tris) buffers were from Sigma-Aldrich. TE (Tris/EDTA) buffer was from Quiagen and made of Tris (10 mM) and ethylenediaminetetraacetic acid (EDTA, $1 \mathrm{mM}$ ) at $\mathrm{pH} 8$ (structures of Tris and EDTA in SM-Scheme 1). A Lab-Line Multi block heater was used and samples were incubated in the dark under an aluminum foil sheet.

\subsubsection{Transmission Electron Microscopy (TEM)}

All data were collected at $120 \mathrm{kV}$ on a Tecnai TEM (FEI) at the eucentric height to ensure that all measurements and electron diffraction (ED) data were accurate for both collection and comparison. The electron diffraction patterns were collected in the microprobe or nanoprobe mode depending on the size of the area to be analyzed. A $7 \mu \mathrm{L}$ drop of the aqueous DNA suspension was placed on a 200 mesh carbon coated copper grid, (TED Pella Inc., Redding, California, USA), and 
allowed to dry for 5 minutes in the dark. The remaining liquid was "whisked" away using a filter paper. The control samples were prepared in the same way in the absence of DNA. The spherical shape of particles was determined by eucentric tilting (over at least an $80^{\circ}$ range) over the particles. Average particle sizes were determined by counting 50 particles from the TEM images for the NP samples using "imageJ" software (NIH).

\subsubsection{Gel Electrophoresis}

$0.8 \%$ agarose gels were freshly prepared by dissolving $0.4 \mathrm{~g}$ of agarose, purchased (Sigma) in TE buffer $(1 \times) .2 .5 \mu \mathrm{L}$ of ethidium bromide was added when the mixture was still in the liquid phase. After solidification, $10 \mu \mathrm{L}$ of specific samples were loaded in each of the 10 wells and the gel was run at $85-90 \mathrm{~V}$ for $75 \mathrm{~min}$.

\subsubsection{Plasmid DNA}

pcDNA 3.1(+)/GFP was amplified following Quiagen protocols. In order to determine plasmid size, a sample of each circular plasmid DNA was incubated with ECORI restriction enzyme and linearized. After running on a $0.8 \%$ agarose gel, the following sizes were deduced from $1 \mathrm{~kb}$ standard ladder (Biolabs): pcDNA 3.1(+)/GFP: $\sim 6 \mathrm{kbp}(3960 \mathrm{kDa})$; pMSCV: $\sim 7 \mathrm{kbp}$; pBABEc: $\sim 6 \mathrm{kbp}$.

\subsubsection{Metal Nanoparticles}

In a $200 \mu \mathrm{L}$ PCR Eppendorf tube, $60 \mu \mathrm{L}$ of a DNA suspension $\left(35 \mathrm{ng} / \mu \mathrm{L}, \sim 5 \times 10^{-13} \mathrm{moles}\right.$, in TE buffer, $\mathrm{pH} 8$ ) was incubated with $10 \mu \mathrm{L}$ of a solution containing $0.5 \mathrm{wt} \%$ chloro trimethylphosphine-gold (I) in acetone $\left(1.6 \times 10^{-4} \mathrm{M}, 1.6 \times 10^{-9}\right.$ moles, referred as the gold phosphine solution) in the dark at $70{ }^{\circ} \mathrm{C}$ in a programmable block heater. This method yielded the formation of $6,8,9,11,18$, and $21 \mathrm{~nm}$ diameter Au NPs after 1, 2, 4, 7, 12, and $15 \mathrm{~h}$ of DNA/metal cations incubation, respectively (Figures 1-3). When the incubation time was extended to 21 hours, the water of the DNA suspension evaporated and condensed on the lid of the PCR Eppendorf tube, causing the DNA, as well as other randomly shaped gold structures present in solution, to aggregate at the bottom of the tube. This aggregation of amorphous DNA and Au material was confirmed by UV-visible spectroscopy [20] (supplementary material). Control experiments with TE buffer and gold phosphine solution were run in the absence of DNA for 1, 2, 4 , and $7 \mathrm{~h}$ at $70{ }^{\circ} \mathrm{C}$, respectively (Figures 2 and 3) and result in randomly sized aggregates. A product yield of $69 \%$ was found for the Au NP formed in the presence of the plasmid, and was calculated via equation 1 below (also see Figure SM-1 for detailed calculations) [21]. For formation of the other metallic NP, ethanol solutions containing $0.5 \mathrm{wt} \%$ of palladium acetate, chromium acetylacetonate, or silver acetate were used. 
Figure 2. (A) The UV-visible spectra of the $\mathrm{Au}$ nanoparticles formed by heating the solution containing the DNA in TE buffer and the gold phosphine at $70{ }^{\circ} \mathrm{C}$ in the dark for 1 $\mathrm{h}$ (blue line), $2 \mathrm{~h}$ (pink line), and $4 \mathrm{~h}$ (red line). Transmission electron microscopy images were taken of these three samples. (A1) TEM image of the sample heated for $1 \mathrm{~h}$, (A2) TEM image of the sample heated for $2 \mathrm{~h}$, and (A3) TEM image of the sample heated for $4 \mathrm{~h}$. (B) The UV-visible spectra of the Au nanoparticles formed in control reactions by heating the solution containing only the gold phosphine and the TE buffer at $70{ }^{\circ} \mathrm{C}$ in the dark for $1 \mathrm{~h}$ (blue line), $2 \mathrm{~h}$ (pink line), and $4 \mathrm{~h}$ (red line). Transmission electron microscopy images were taken of these three control samples. (B1) TEM image of the control sample heated for $1 \mathrm{~h}$, (B2) TEM image of the control sample heated for $2 \mathrm{~h}$, and (B3) TEM image of the control sample heated for $4 \mathrm{~h}$.
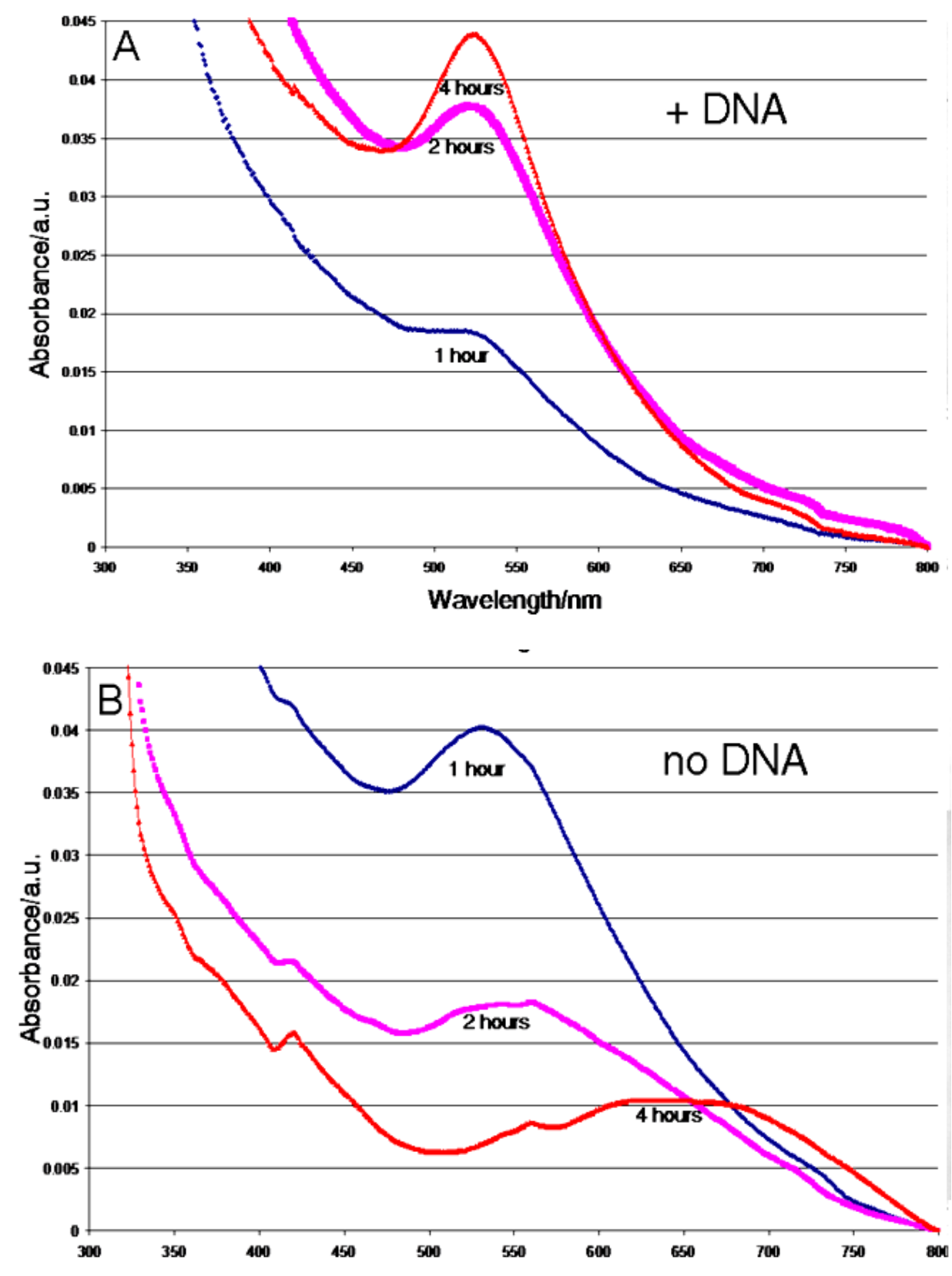
Figure 2. Cont.
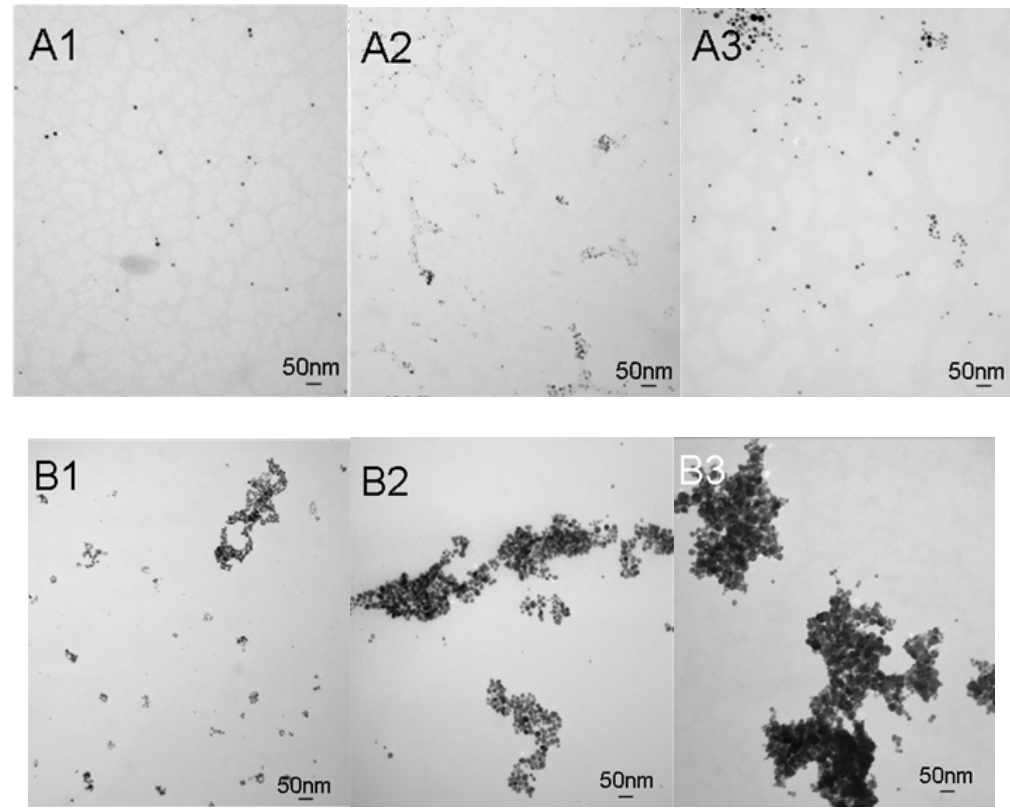

Figure 3. (A) UV-visible spectrum and corresponding TEM image (A1) of DNA samples incubated with gold phosphine solution for $7 \mathrm{~h}$ at $70{ }^{\circ} \mathrm{C}$ in the dark; Inset panel: higher magnification of sample in A1. (B) UV-visible spectrum and corresponding TEM image (B1) of TE buffer control incubated with gold phosphine solution under the same conditions.
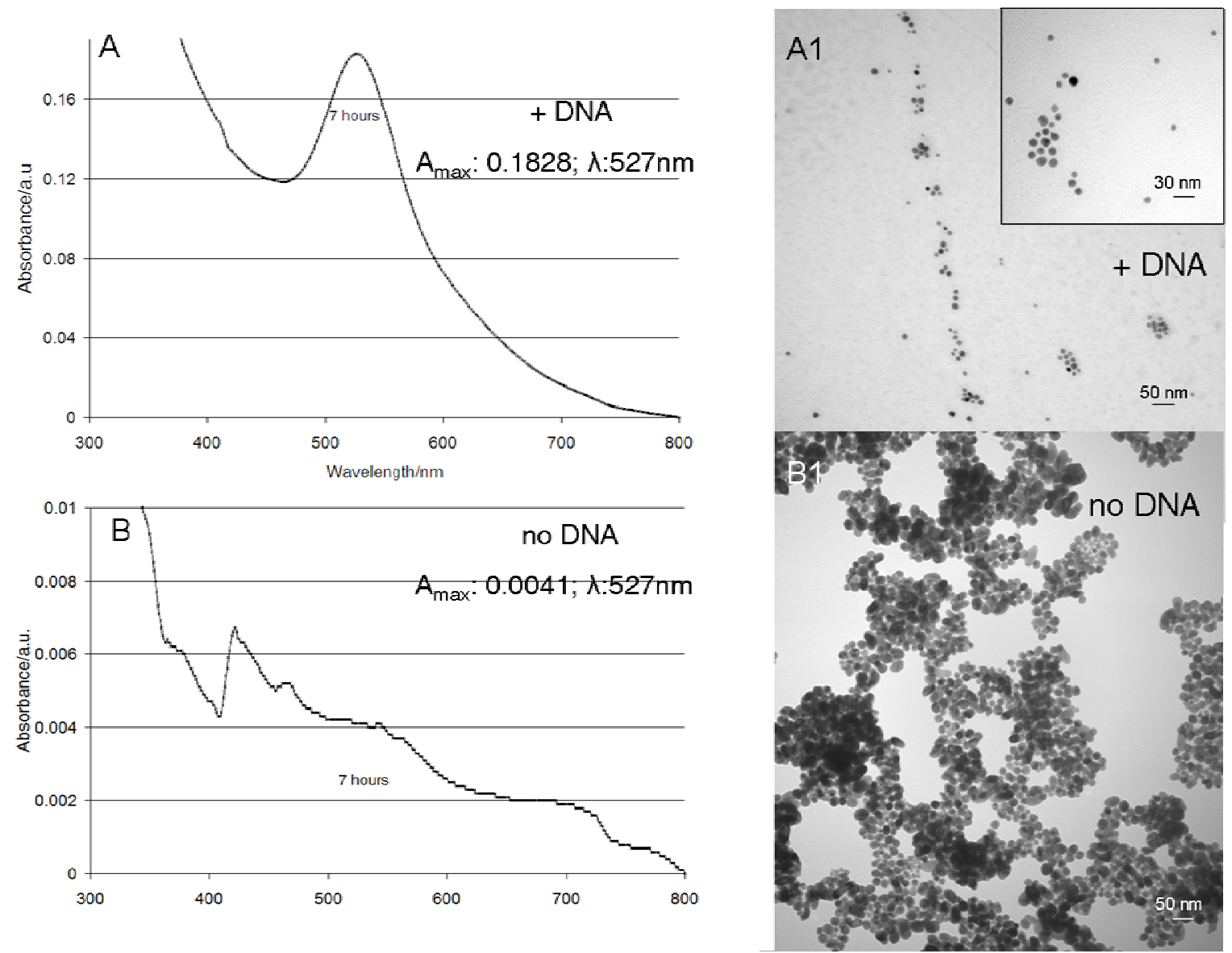


\section{Results and Discussion}

The synthetic parameters and trends in NP formation were evaluated with one plasmid DNA and gold phosphine, and these data were used as a guide to fabricate $\mathrm{NP}$ of $\mathrm{Ag}, \mathrm{Pd}$, and $\mathrm{Cr}$. UV-visible spectra of the solution from control experiments with only the gold phosphine and the TE buffer incubated for $1 \mathrm{~h}$ at $70{ }^{\circ} \mathrm{C}$ showed the presence of Au NP (Figure SM-2), and was similar to those with the plasmid DNA under the same conditions, suggesting that the TE buffer may act as an initial seeding entity. Other amines are known to serve as reducing agents [22-25], and the DNA can serve as a source of electrons at elevated temperatures. Preparations with non-amine buffers such as phosphate do not yield Au NP. UV-visible spectra from the $2 \mathrm{~h}$ and the $4 \mathrm{~h}$ control experiments showed a progressive diminishment of the peak corresponding to the Au NP absorption as well as an increasing red shift, indicating the formation of larger and more amorphous Au materials. These latter controls confirm that the plasmid DNA is responsible for both the size control and the narrow distribution of the fabricated Au NPs (Figures 2 and 3). Furthermore, in the absence of DNA, amorphous gold aggregates were observed after $7 \mathrm{~h}$ of incubation (Figure 3). The role of the DNA as a mold also was deduced by comparing the UV-visible spectra with an analysis of the fate of the DNA by gel electrophoresis (Figures 2, 3 and SM-3, SM-4, SM-5). After a four hour incubation experiment, the DNA gels showed a substantial modification of the initial plasmid topology and eventually the DNA is not observed (Figure SM-2, compare lanes 2 and 10). The UV-visible spectra indicate increased formation of the Au NP with time, but not an increase in NP size (Figure SM-1). The ratio of initial DNA condensation states, supercoiled versus relaxed, dictates the dispersity of the NP products (Figure SM-3, lanes 2 and 5). Fabrication of narrowly dispersed particles was obtained concomitant with degradation of the DNA, as observed starting around two hours of incubation time with the gold phosphine (Figure SM-3, lanes 2 and 5). Our hypothesis is that degraded DNA segments maintain particle dispersion by inhibiting aggregation during incubation, although we cannot exclude the possibility that the DNA from the plasmid surrounds the particle (Figures SM-6 and SM-7). The maximum amount of $\mathrm{Au}$ NP is reached by seven hours of incubation as revealed by comparison of the UV-visible absorption peaks shown in Figure 3(A) and 3(B) and the corresponding TEM images. The size tunability of the $\mathrm{Au}$ NP versus incubation time was verified by TEM measurements, and is supported by the corresponding UV-visible spectra (Figures 2 and 3).

The metallic nature of the Au NPs was confirmed by superimposing the ED pattern obtained from the experimental samples with that of a metallic gold standard (Figure 4) [26]. The spherical shape of the $\mathrm{Au}$ NP were determined by eucentric tilting (see experimental and supplementary material). The relative proportions ( 3200:1 Au:plasmid or 1:2 Au:base pairs) and concentrations of plasmid DNA and gold salt outlined in the experimental section reproducibly yield the narrow dispersity NP. These conditions were found empirically. With the same amount of gold salt, dilution of the plasmid DNA concentration by 50 -fold results in a broadening of the UV-visible spectra of the Au NP indicating a much broader distribution of NP. A 5-fold increase of plasmid DNA concentration yielded much fewer particles (Figure SM-8), perhaps because too much of the gold is bound by the plasmid thereby inhibiting NP growth (1:10 Au:base pair). Furthermore, the UV-visible spectra of Au NP from the 50 fold diluted sample containing plasmid DNA, was nearly 
identical to the spectra of the TE buffer/Au controls. The reaction does not yield NP when the solvent evaporates (Figure SM-9). These observations suggest that a balance between the relative quantities of the metal salts, the plasmid DNA, and the buffer are necessary to ensure the narrow dispersity of the NP. After about two hours, the size of the NP increases but the dispersity of the NP narrows, and this is reflected in the UV-visible spectra as a progressive red shift without broadening. This observation is consistent with previous studies correlating UV-visible spectra with NP size [20]. Nucleation of the nanoparticles initiating inside the toroid in the minor and major grooves of DNA, where cationic binding is often observed [27], may explain the size control of the Au NPs (see supplementary materials).

Figure 4. ED pattern of metallic gold standard solution (blue) superimposed on the experimental ED pattern obtained from Au NPs analysis (red) where the overlap indicates the DNA template prepared sample is metallic Au.

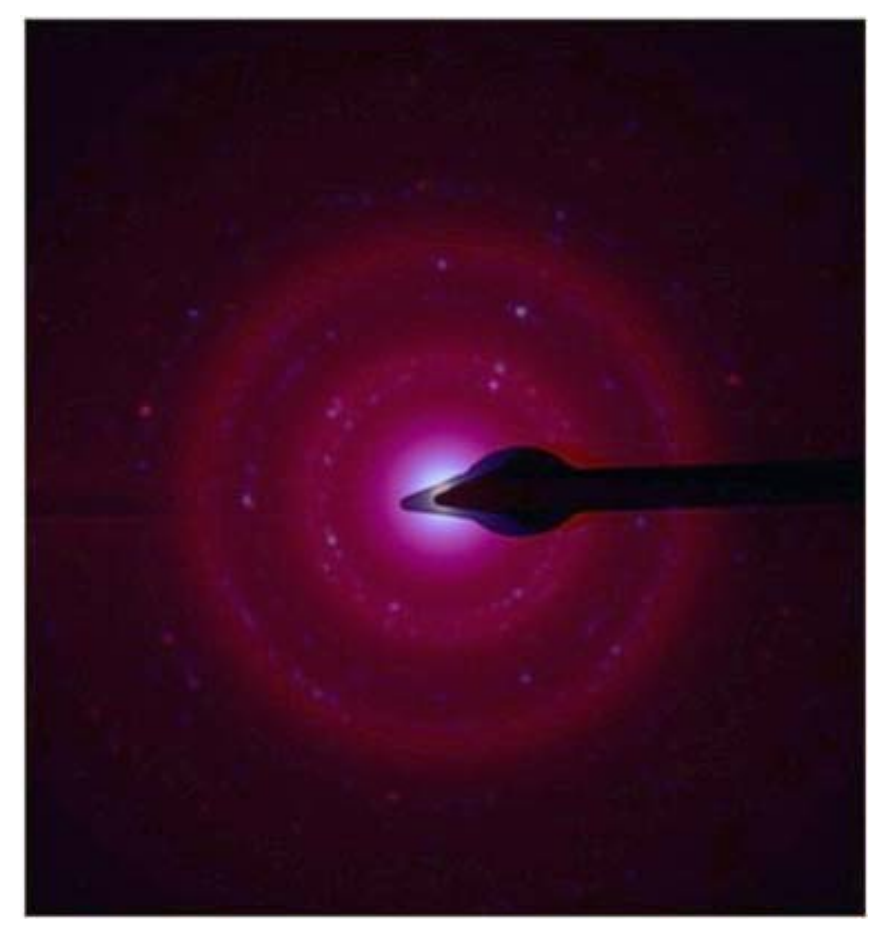

The overall yield of the NP can be estimated from equation 1 . After a typical $4 \mathrm{~h}$ incubation time at $70{ }^{\circ} \mathrm{C}$, the yield is about $8 \%$, but the yield increases to about $70 \%$ after two weeks at room temperature (Figure SM-1). This indicates that incubation at elevated temperatures initiates the NP formation process. Histograms of the size distribution of the Au NP under several conditions, and the control TE buffer are shown in Figures 5 and 6. UV-Visible spectra from Figure 7 show that different plasmid DNA constructs with similar base pair count (approximately 6kbps) yield narrowly dispersed gold nanoparticles indicating that a specific plasmid DNA is not necessary.

$$
\begin{gathered}
\text { Yield NP: } \mathrm{C}_{\text {initial NP }} / \mathrm{C}_{\text {synthesized NP }} \% \\
\mathrm{C}_{\text {initial NP }}=\mathrm{N}_{\text {tot }} / \mathrm{N}_{\mathrm{A}} \mathrm{V} \mathrm{N} \\
\mathrm{C}_{\text {synthesized NP }}=\mathrm{A} / \varepsilon
\end{gathered}
$$


Figure 5. (A) Histogram of Au NP size distributions corresponding to samples incubated with plasmid DNA in TE buffer for $1 \mathrm{~h}$ (S1, blue), $2 \mathrm{~h}$ (S2, purple), $4 \mathrm{~h}$ (S3, red), and $7 \mathrm{~h}$ (S4, black). After $4 \mathrm{~h}$ there is a progressive narrowing of the distribution and an increase in particle size that is in agreement with the red shifts observed in the UV-visible spectra (Figures 1 and 2). (B) Histogram of Au NP sizes corresponding to samples incubated with plasmid DNA for $12 \mathrm{~h}$ (S1, dark blue) and $15 \mathrm{~h}$ (S2, pink). TEM images of the Au NP from $12 \mathrm{~h}$ (dark blue) and $15 \mathrm{~h}$ (pink) incubations at $70{ }^{\circ} \mathrm{C}$.

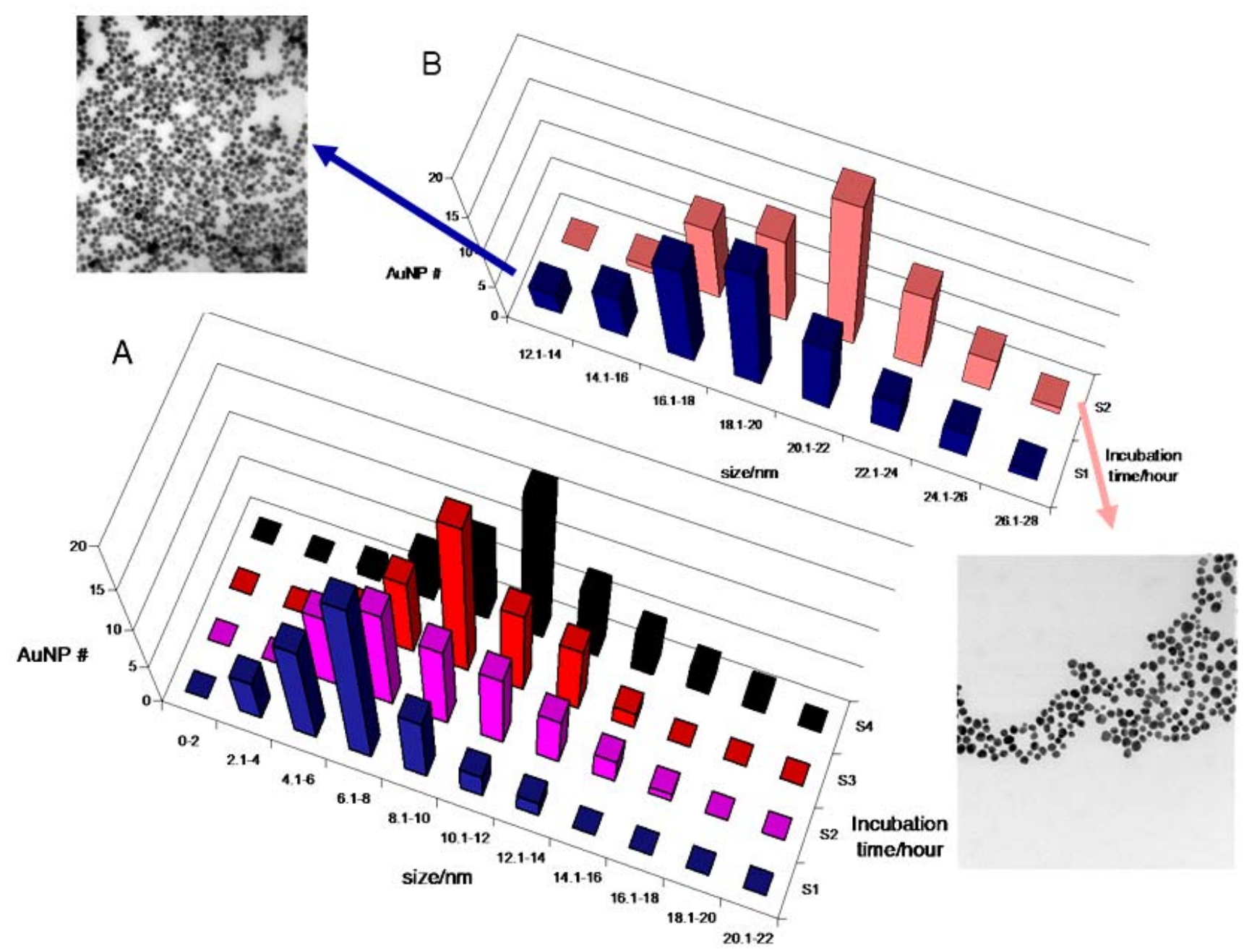


Figure 6. Histogram of NP size distributions of control samples in TE buffer without plasmid DNA incubated for $1 \mathrm{~h}$ (S1, blue), $2 \mathrm{~h}$ (S2, purple), $4 \mathrm{~h}$ (S3, red), and $7 \mathrm{~h}$ (S4, black). Despite the high level of aggregation, the particles were still counted individually. The level of particle aggregation was greatest in the $7 \mathrm{~h}$ sample (Figure 3). No correlation between the NP size and the incubation time was observed.

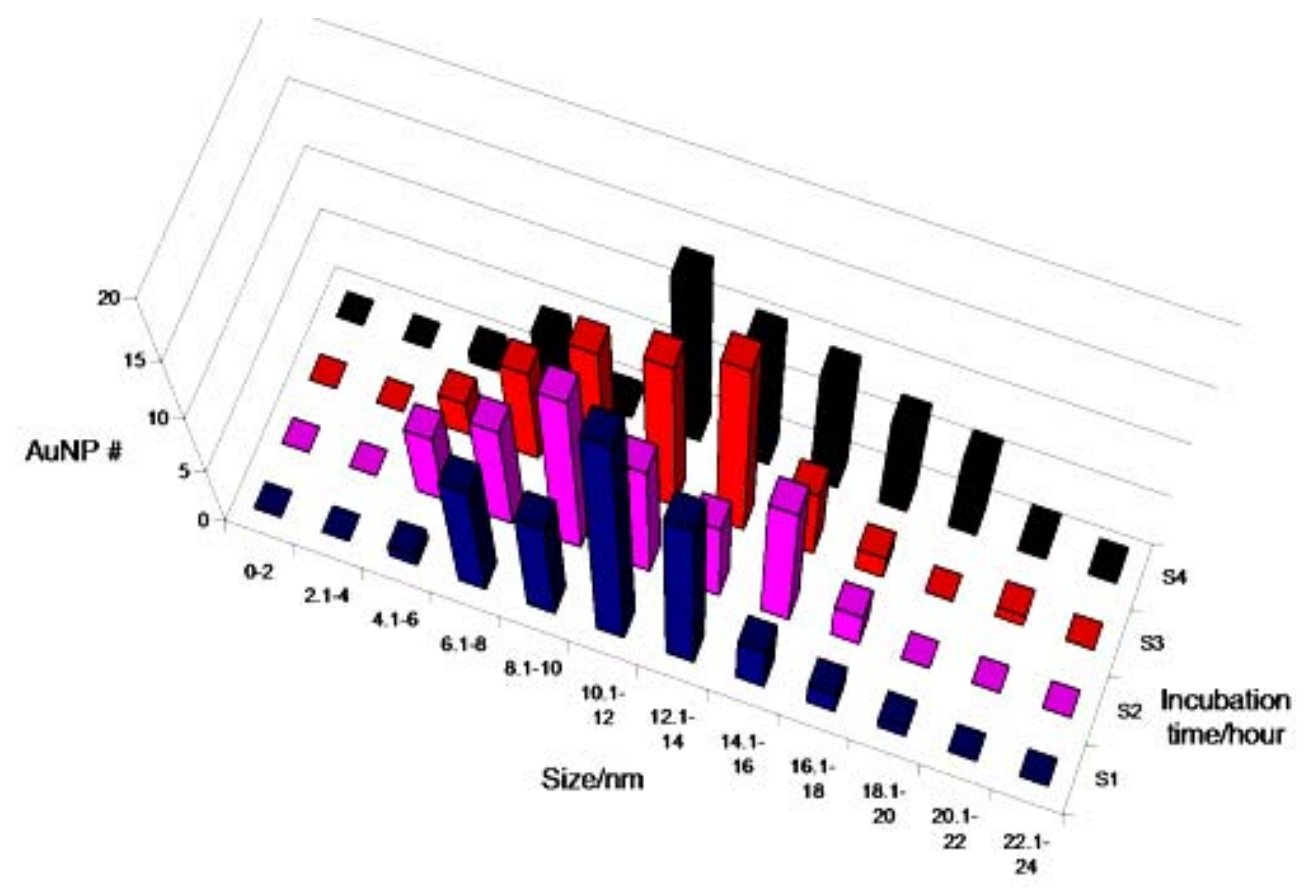

Figure 7. UV-visible spectra of three different plasmid DNA samples incubated in the dark at $70{ }^{\circ} \mathrm{C}$ for 2 and $4 \mathrm{~h}$. The $\lambda_{\max }$ and half-width of the peaks indicate that these plasmids yield $\mathrm{Au}$ NPs with similar size and distribution. The spikes at $\sim 550 \mathrm{~nm}$ and $\sim 740 \mathrm{~nm}$ are instrumental artifacts.

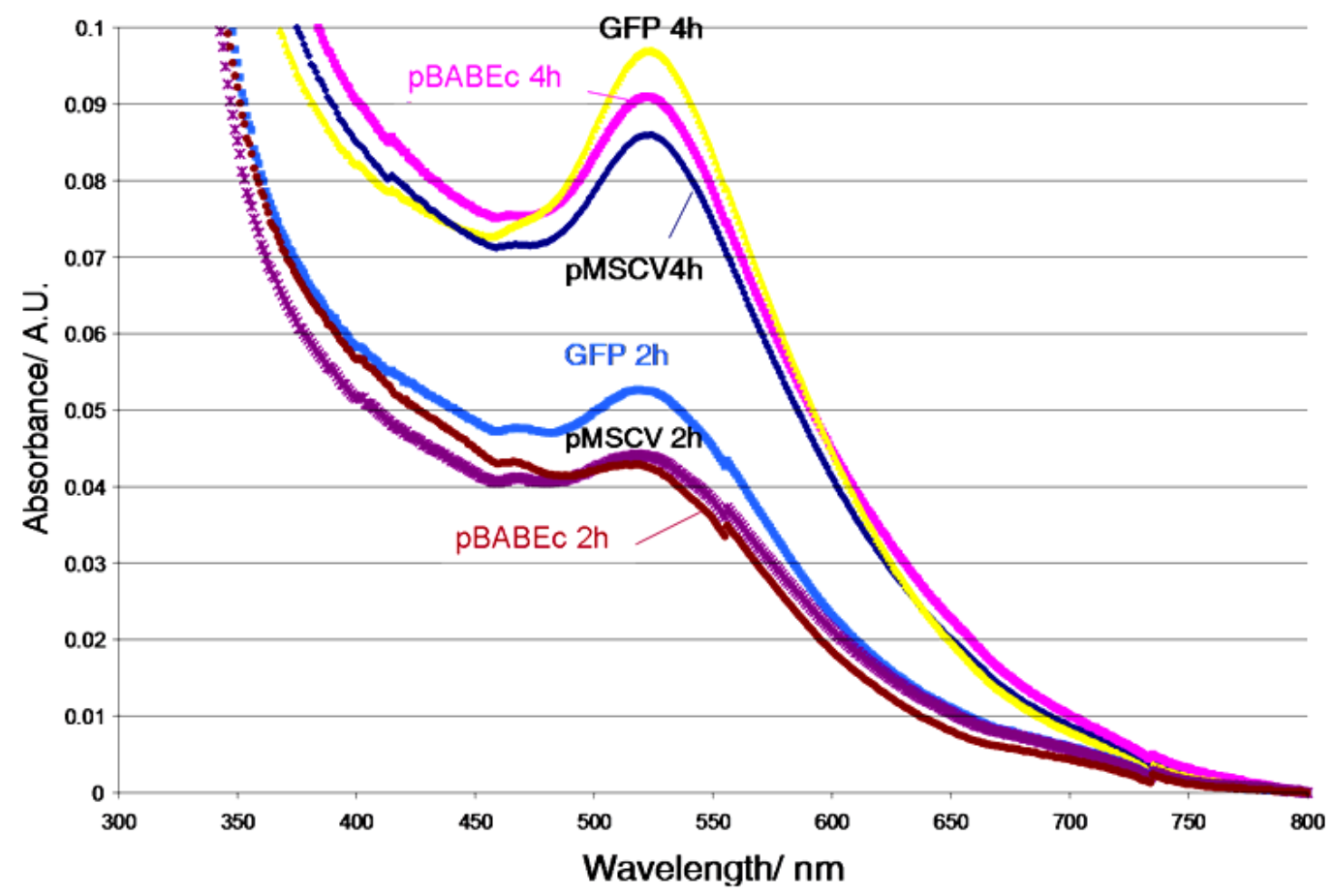




\section{Ag, Pd, and Cr Nanoparticles}

Metallic nanoparticles of Pd are widely used as catalysts for organic transformations and coupling reactions [28-30]. Silver nanoparticles are exploited as sensors in surface enhanced Raman and other methods [31-35]. Chromium nanoparticles are proposed for a variety of photonics applications, including in solar energy harvesting [36]. Therefore, facile and greener synthetic methods resulting in narrowly dispersed nanoparticles of these metals are of significant interest. The same procedures and considerations are used to make metallic nanoparticles of $\mathrm{Pd}, \mathrm{Ag}$, and $\mathrm{Cr}$. Using our optimized conditions from the above Au NP experiments, the plasmid DNA is incubated at $70{ }^{\circ} \mathrm{C}$ between $10 \mathrm{~h}$ and $17 \mathrm{~h}$ depending on the metal ion used. These systems are characterized by UV-visible spectroscopy, TEM, and energy dispersive x-ray microanalysis (EDAX) (Figures 8 and 9). These data are consistent with those reported in the aforementioned literature.

The mechanism of metallic NP formation inside a variety of organic and biological structures has been discussed in terms of increased concentration of nucleation sites on the interior surface versus the exterior surface, the topology of the nanoreactor, and in terms of the reaction conditions $[37,38]$.

Figure 8. The UV-visible spectra of nanoparticles of palladium (purple), silver (blue), and chromium (green) compared to that of gold (yellow) are consistent with data reported previously.

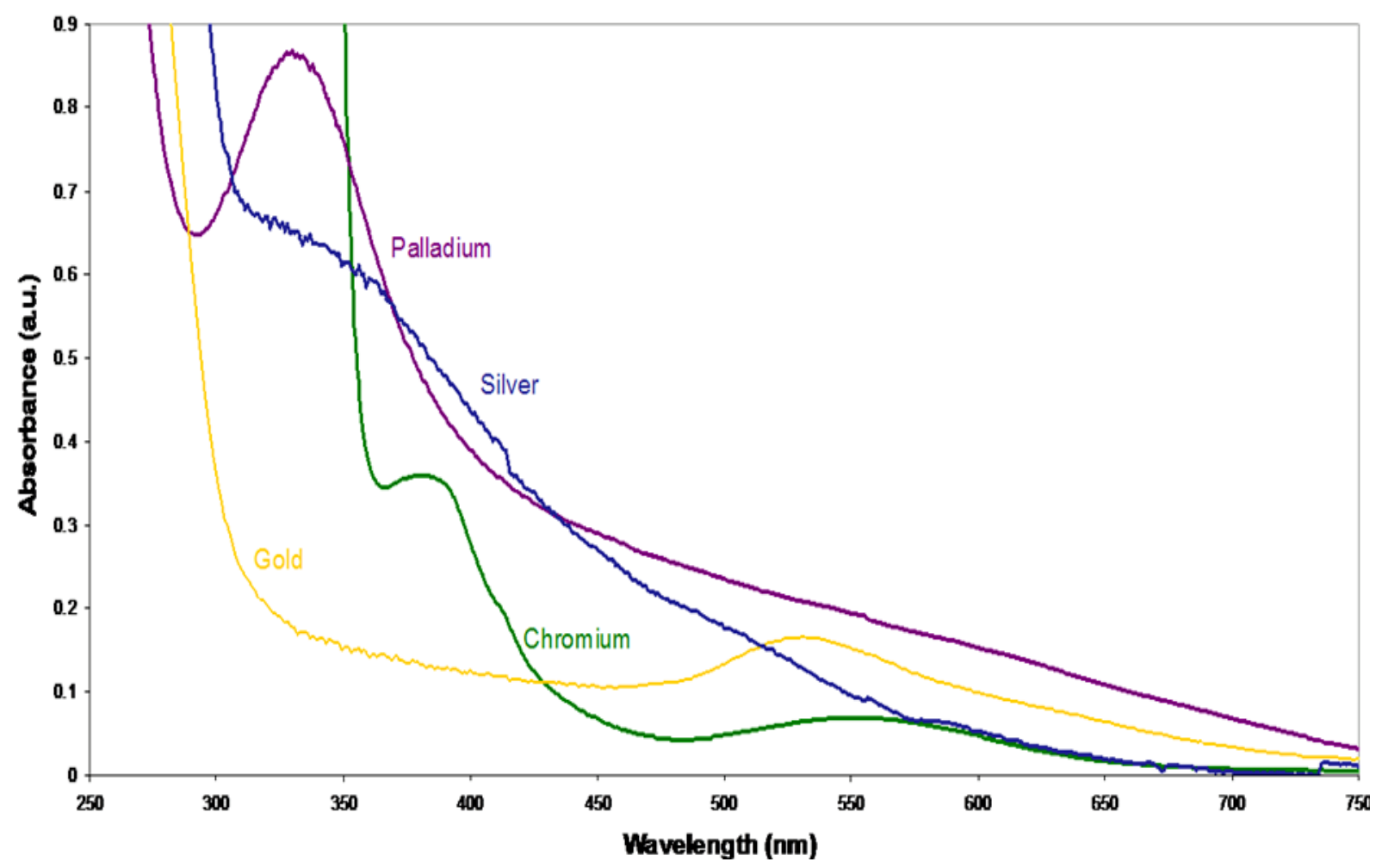


Figure 9. Left column: Representative TEM images of nanoparticles composed of different metals that were formed by heating a solution of the metal ion precursor with the plasmid DNA in Tris buffer at $70{ }^{\circ} \mathrm{C}$ for various times. The Au reaction was heated for $12 \mathrm{~h}$, the Pd reaction was heated for $17 \mathrm{~h}$, the Ag reaction was heated for $10 \mathrm{~h}$, and the $\mathrm{Cr}$ reaction was heated for $10 \mathrm{~h}$. From the top are the TEM of the $\mathrm{Au}, \mathrm{Pd}, \mathrm{Ag}$, and $\mathrm{Cr}$ nanoparticles. Right column: EDAX Netcounts (sample area minus control area) spectra indicate the composition of the metallic nanoparticles found in the TEM images. From the top are the EDAX spectra of $(\mathbf{A}) \mathrm{Au},(\mathbf{B}) \mathrm{Pd},(\mathbf{C}) \mathrm{Ag}$. For the Cr nanoparticles (D), the Netcounts method was not used so the x-ray scattered lines from the carbon coated copper grid, show up in the spectrum (indicated by the $\mathrm{Cu}$ peak).

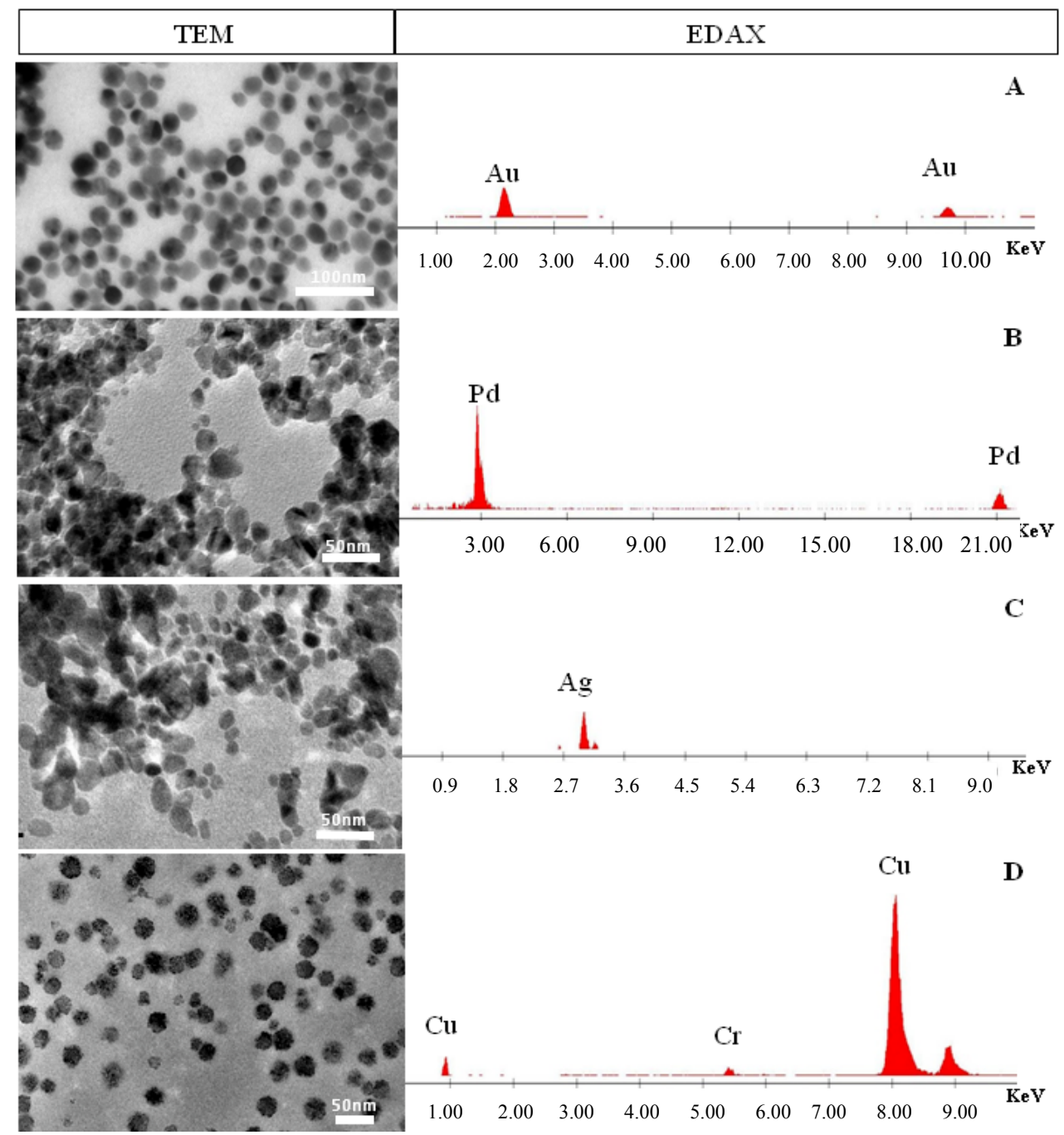

\section{Conclusions}

The results demonstrate the ease of synthesis of size tunable nearly spherical nanoparticles of $\mathrm{Au}$, and narrowly dispersed NP of several types of metals, that exploits the toroid topology of plasmid DNA as a mold in concert with the slow, temperature controllable oxidation of an amine buffer. While our previous report used UV light to catalyze the oxidation of the DNA and concomitant reduction of the metal cations [18], herein we employ the application of heat to initiate oxidation of the TE buffer to reduce the metal cations. The multi block heater ensures 
exact temperature control over a predetermined amount of time while using minimal energy. The stabilization of the metallic NP is mediated by the plasmid DNA fragments. These mild synthetic conditions makes this method environmentally more sustainable, while the minimal steps and the variety of possible plasmids with differences in topology and size enables widespread applications and feasibility for the synthesis of metallic NPs.

\section{Acknowledgments}

This work was supported by the NSF (CHE-0847997) to C.M.D. R.S. was supported by the Harlem Children's Society. Hunter College science infrastructure is supported by the National Science Foundation, the National Institutes of Health including the RCMI program (G12-RR-03037), and the City University of New York. We thank Dr. Alfredo Toschi for his plasmid amplification work and Professor Yujia $\mathrm{Xu}$ for her advice.

\section{Conflict of Interest}

The authors declare no conflict of interest.

\section{References}

1. Sun, Y.; Xia, Y. Shape-controlled synthesis of gold and silver nanoparticles. Science 2002, 298, 2176-2179.

2. Wagner, J.; Köhler, J.M. Continuous synthesis of gold nanoparticles in a microreactor. Nano Lett. 2005, 5, 685-691.

3. Jana, N.R.; Gearheart, L.; Murphy, C.J. Seeding growth for size control of 5-40 nm diameter gold nanoparticles. Langmuir 2001, 17, 6782-6786.

4. Shanmugam, S.; Viswanathan, B.; Varadarajan, T.K. A novel single step chemical route for noble metal nanoparticles embedded organic-inorganic composite films. Mater. Chem. Phys. 2006, 95, $51-55$.

5. Hiramatsu, H.; Osterloh, F.E. A simple large-scale synthesis of nearly monodisperse gold and silver nanoparticles with adjustable sizes and with exchangeable surfactants. Chem. Mater. 2004, 16, 2509-2511.

6. Martinez-Hurtado, J.L. Metallic nanoparticle block copoloymer vesicles with enhanced optical properties. Nanomaterials 2011, 1, 20-30.

7. Tiwari, P.; Vig, K.; Dennis, V.; Singh, S. Functionalized gold nanoparticles and their biomedical applications. Nanomaterials 2011, 1, 31-63.

8. Kamat, P.V. Photophysical, photochemical and photocatalytic aspects of metal nanoparticles. J. Phys. Chem. B 2002, 106, 7729-7744.

9. Campelo, J.M.; Conesa, T.D.; Gracia, M.J.; Jurado, M.J.; Luque, R.; Marinas, J.M.; Romero, A.A. Microwave facile preparation of highly active and dispersed SBA-12 supported metal nanoparticles. Green Chem. 2008, 10, 853-858. 
10. Sondi, I.; Skapin, S.D. A biomimetic nano-scale aggregation route for the formation of submicron-size colloidal calcite particles. In Biomimetics Learning from Nature; Mukherjee, A., Ed.; InTech: West Palm Beach, FL, USA, 2010.

11. Okuda, M.; Kobayashi, Y.; Suzuki, K.; Sonoda, K.; Kondoh, T.; Wagawa, A.; Kondo, A.; Yoshimura, H. Self-organized inorganic nanoparticle arrays on protein lattices. Nano Lett. 2005, 5, 991-993.

12. Ensign, D.; Young, M.; Douglas, T. Photocatalytic synthesis of copper colloids from $\mathrm{Cu}(\mathrm{II})$ by the ferrihydrite core of ferritin. Inorg. Chem. 2004, 43, 3441-3446.

13. Butts, C.; Swift, J.; Kang, S.-G.; Costanzo, L.D.; Christianson, D.W.; Saven, J.G.; Dmochowski, I.J. Directing noble metal ion chemistry within a designed ferritin protein. Biochemistry 2008, 47, 12729-12739.

14. Mandal, D.; Bolander, M.; Mukhopadhyay, D.; Sarkar, G.; Mukherjee, P. The use of microorganisms for the formation of metal nanoparticles and their application. Appl. Microbiol. Biotech. 2006, 69, 485-492.

15. Shchukin, D.G.; Sukhorukov, G.B. Nanoparticle synthesis in engineered organic nanoscale reactors. Adv. Mater. 2004, 16, 671-682.

16. Ravindra, P. Protein-mediated synthesis of gold nanoparticles. Mater. Sci. Eng. B 2009, 163, 93-98.

17. Slocik, J.M.; Naik, R.R.; Stone, M.O.; Wright, D.W. Viral templates for gold nanoparticle synthesis. J. Mater. Chem. 2005, 15, 749-753.

18. Samson, J.; Varotto, A.; Nahirney, P.C.; Toschi, A.; Piscopo, I.; Drain, C.M. Fabrication of metal nanoparticles using toroidal plasmid DNA as a sacrificial mold. ACS Nano 2009, 3, 339-344.

19. Kimling, J.; Maier, M.; Okenve, B.; Kotaidis, V.; Ballot, H.; Plech, A. Turkevich method for gold nanoparticle synthesis revisited. J. Phys.Chem. B 2006, 110, 15700-15707.

20. Haiss, W.; Thanh, N.T.K.; Aveyard, J.; Fernig, D.G. Determination of size and concentration of gold nanoparticles from UV-vis spectra. Anal. Chem. 2007, 79, 4215-4221.

21. Liu, X.; Atwater, M.; Wang, J.; Huo, Q. Extinction coefficient of gold nanoparticles with different sizes and different capping ligands. Colloid Surface B 2007, 58, 3-7.

22. Aslam, M.; Fu, L.; Su, M.; Vijayamohanan, K.; Dravid, V.P. Novel one-step synthesis of amine-stabilized aqueous colloidal gold nanoparticles. J. Mater. Chem. 2004, 14, 1795-1797.

23. Leff, D.V.; Brandt, L.; Heath, J.R. Synthesis and characterization of hydrophobic, organically-soluble gold nanocrystals functionalized with primary amines. Langmuir 1996, 12, 4723-4730.

24. Newman, J.D.S.; Blanchard, G.J. Formation of gold nanoparticles using amine reducing agents. Langmuir 2006, 22, 5882-5887.

25. Subramaniam, C.; Tom, R.T.; Pradeep, T. On the formation of protected gold nanoparticles from $\mathrm{Aucl}_{4}{ }^{-}$by the reduction using aromatic amine. J. Nanopart. Res. 2005, 7, 209-217.

26. Samson, J.; Nahirney, P.C.; Drain, C.M.; Piscopo, I. Simplifying electron diffraction pattern identification of mixed-material nanoparticles. Microsc. Today 2011, 19, 38-41.

27. Hud, N.; Polak, M. DNA-cation interactions: The major and minor grooves are flexible ionophores. Curr. Opin. Struct. Biol. 2001, 11, 293-301. 
28. Hu, J.; Liu, Y. Pd nanoparticle aging and its implications in the suzuki cross-coupling reaction. Langmuir 2005, 21, 2121-2123.

29. Chandrasekhar, V.; Suriya Narayanan, R.; Thilagar, P. Organostannoxane-supported palladium nanoparticles. Highly efficient catalysts for suzuki-coupling reactions. Organometallics 2009, 28, 5883-5888.

30. Watt, J.; Cheong, S.; Toney, M.F.; Ingham, B.; Cookson, J.; Bishop, P.T.; Tilley, R.D. Ultrafast growth of highly branched palladium nanostructures for catalysis. ACS Nano 2009, 4, 396-402.

31. Maduraiveeran, G.; Ramaraj, R. Potential sensing platform of silver nanoparticles embedded in functionalized silicate shell for nitroaromatic compounds. Anal. Chem. 2009, 81, 7552-7560.

32. Encina, E.R.; Coronado, E.A. Plasmon coupling in silver nanosphere pairs. J. Phys. Chem. C 2010, 114, 3918-3923.

33. Mitsuishi, M.; Tanaka, H.; Obata, M.; Miyashita, T. Plasmon-enhanced luminescence from ultrathin hybrid polymer nanoassemblies for microscopic oxygen sensor application. Langmuir 2010, 26, 15117-15120.

34. Ramesh, G.V.; Radhakrishnan, T.P. A universal sensor for mercury (Hg, HgI, HgII) based on silver nanoparticle-embedded polymer thin film. ACS Appl. Mat. Interface. 2011, 3, 988-994.

35. Wang, W.; Shi, X.; Kariuki, N.N.; Schadt, M.; Wang, G.R.; Rendeng, Q.; Choi, J.; Luo, J.; Lu, S.; Zhong, C.-J. Array of molecularly mediated thin film assemblies of nanoparticles: Correlation of vapor sensing with interparticle spatial properties. J. Am. Chem. Soc. 2007, 129, 2161-2170.

36. Pribik, R.; Aslan, K.; Zhang, Y.; Geddes, C.D. Metal-enhanced fluorescence from chromium nanodeposits. J. Phys. Chem. C 2008, 112, 17969-17973.

37. Kim, S.-W.; Park, J.; Jang, Y.; Chung, Y.; Hwang, S.; Hyeon, T.; Kim, Y.W. Synthesis of monodisperse palladium nanoparticles. Nano Lett. 2003, 3, 1289-1291.

38. Patolsky, F.; Weizmann, Y.; Lioubashevski, O.; Willner, I. Au-nanoparticle nanowires based on dna and polylysine templates. Angew. Chem. Int. Ed. 2002, 41, 2323-2327.

(C) 2011 by the authors; licensee MDPI, Basel, Switzerland. This article is an open access article distributed under the terms and conditions of the Creative Commons Attribution license (http://creativecommons.org/licenses/by/3.0/). 